\title{
Properties and Processes of Crustal Fault Zones: Volume II
}

\author{
Yehuda Ben-Zion ${ }^{1}$ and Antonio Rovelli ${ }^{2}$
}

\section{Introduction}

Active faults and earthquake rupture zones are largely buried under miles of rocks. Due to the effects of attenuation, typical seismological and other geophysical data lack detailed information on faulting processes. For these reasons as well as the inherent complexity of faulting, many fundamental questions on the structure and processes of fault zones in relation to earthquake properties and generated ground motion remain unanswered. To discuss the state of the art in the field, the 40th Workshop of the International School of Geophysics, titled "Properties and Processes of Crustal Fault Zones", was held May 18-24, 2013, in the Ettore Majorana Foundation and Centre for Scientific Culture of Erice, Sicily. The papers in a previous volume I and the present volume II discuss observational and theoretical results based on presentations at the workshop and additional contributions that advance the understanding of earthquakes and faults. Topics covered in this volume include imaging of fault zones and the crust with seismic and other signals, microstructural analyses of fault zone rocks, long paleoseismic records of large earthquakes, inferences on stress, stress drops and fault geometries from seismological and geological data, properties of dynamic ruptures, generation and healing of rock damage, temporal changes of seismic properties, postseismic deformation, and scaling of earthquake rupture areas with moment.

1 Department of Earth Sciences, University of Southern California, Los Angeles, CA 90089-0740, USA. E-mail: benzion@usc.edu

2 Istituto Nazionale di Geofisica e Vulcanologia, Seismology and Tectonophysics, Rome, Italy.
In the first paper of the volume, Zigone et al. use Rayleigh and Love waves constructed from the ambient seismic noise to obtain a 3D model of $\mathrm{S}$ wave velocities in the southern California plate-boundary region. The results show clear damage zones in the top few kilometres around the San Andreas, San Jacinto, and Elsinore faults, and velocity contrasts across various fault sections, which augment earthquake tomography images at greater depth. Additional findings include 2- $\theta$ azimuthal anisotropy with fast directions parallel to geometrically simple fault sections and mixed directions in complex areas. Bennington et al. develop a method for joint inversion of $\mathrm{P}$ wave velocity and electrical resistivity using a normalized cross-gradient constraint, and apply it to obtain a structural profile across the San Andreas Fault Observatory at Depth (SAFOD). The results provide strong constraints on several key geological units and are used to infer possible fluid-rich regions in the fault zone structure. Bradbury et al. describe the microstructure and chemical composition of faultrelated rocks from the SAFOD borehole and surface outcrops that may be useful analogs for San Andreas Fault rocks. The observed rock textures are consistent with largely aseismic deformation punctuated by seismic slip. The mineralogy and whole-rock geochemistry indicate that the fault zone experienced transient fluid-rock interactions.

Ferrarini et al. constrain the fault segmentation pattern and regional stress tensor in the intra-Apennine area of central Italy using geological and seismological fault-slip data associated with the Colfiorito $1997 \mathrm{Mw} 6.0$ and L'Aquila 2009 Mw 6.1 seismic sequences. The results indicate a prevailing tensional regime involving a subhorizontal NE-SW minimum stress axis and only minor strike-slip regimes. The findings are at odds with results of other studies indicating wide areas characterized by strike- 
slip deformation during the Colfiorito and L'Aquila sequences. Vannoli et al. investigate the fault system of the Po Plain in northern Italy buried beneath several kilometers of sediments. The area corresponds to a convergence of two orogens, the Southern Alps and the Northern Apennines, and is characterized by high seismic risk due to a concentration of population centers, industrial activities, and critical infrastructure. Potential seismogenic faults are identified, described, and organized at a national level in a catalogue of sources for seismic hazard assessment.

Rockwell et al. describe a long paleoseismic record from the San Jacinto fault near Anza, California, with 21 surface ruptures, of which at least 15 are inferred to reflect large earthquakes. The long record may indicate mode-switching from earlier quasi-periodic events to clustered earthquakes over the last 1,000 years. Correlations with paleoseismic data beyond the Hemet step-over to the NW suggest that most events at the different locations are distinct. Some paleo-events at sites on the San Jacinto and San Andreas faults near their intersection may be correlated, but the correlation does not extend to the site near Anza. Ozakin and Ben-Zion use analysis of receiver functions to investigate the geometry of the Moho interface in the southern California plateboundary region. The results show large undulations of the Moho topography along the NE-SW direction and possible vertical Moho offsets of about $8 \mathrm{~km}$ across the San Andreas and San Jacinto faults close to their intersection. A section of very shallow Moho near the Salton Trough produces large Moho offsets at its margins. Significant regional changes in the Moho depth are correlated with regions where faults in the brittle crust have large geometrical complexity.

Cianfarra and Salvini use a computer algorithm to analyze lineaments from the NW part of the Paleogene fold-thrust belt of Spitsbergen in the Svalbard Archipelago. The data range from satellite images to digital maps on regional and local scales. The analysis indicates a large-scale $\mathrm{N}-\mathrm{S}$ lineament domain and another deformation set associated with the West Spitsbergen fold and thrust belt. The results are interpreted with a model consisting of a thin brittle upper layer over a ductile lower crust. Prante and Evans describe textures and microstructures of pseudotachylyte, hydrothermal alteration, and cataclasis along exhumed faults from the central Sierra Nevada in California. Analyses of particle roundness and nearest-neighbor properties are shown to be useful for separating cataclasite and pseudotachylyte that have undergone hydrothermal alteration. Cross-cutting zones of hydrothermal alteration and calcite deformation twins indicate elevated fault zone temperature compared to the country rock.

Pelties et al. simulate dynamic ruptures on a frictional interface in 3D models that include low velocity fault zones with possible depth-dependent width and velocity contrast. The results show that wave reflections from the edges of the fault zone can cause slip arrest and transition to a pulse-like rupture with short rise times. Unloading waves generated when the rupture reaches the free surface can also lead to pulse-like rupture with longer depth-dependent rise times. The first mechanism is dominant for hypocenters inside the low velocity zone, while the second is dominant for hypocenters deeper than a shallow low velocity zone. $\mathrm{Xu}$ et al. simulate dynamic ruptures on a frictional interface in a $2 \mathrm{D}$ inplane setting with off-fault brittle damage accounting for reduction of elastic properties in yielding zones. The spontaneous reduction of elastic moduli near the fault during rupture propagation modifies the subsequent rupture properties and local wave propagation phenomena in several ways. These include rupture transition from a crack-like to a detached pulse, possible generation of a train of pulses, quasi-periodic modulation of slip rates, and asymmetric nearfault motion with higher amplitudes and longer durations on the side with reduced elastic moduli.

Richard et al. discuss laboratory observations on generation and healing of fractures in porous limestone samples. Impact dynamic loading with a split Hopkinson pressure bar produces a series of radial and circular microfractures and incipient pulverization at the sample center subjected to the highest strain rate. Healing involving mechanical and chemical compaction during stationary contact at room temperature under stress for three months, with percolation of supersaturated fluids for five weeks, produces faster closure of small fractures than larger ones. Wang and Ma analyze postseismic reduction of Qs in the hanging wall of the 1999 Chi-chi 
earthquake in Taiwan. Two independent techniques, analysis of single-path Qs and Qs tomography, indicate a $35 \%$ reduction of Qs over a two-year period following the mainshock. The significant reduction of Qs is accompanied by a $1 \%$ decrease of Vs revealed by repeating earthquake waveforms. These findings are interpreted in terms of postseismic fluid redistribution, leading to high pore fluid in the hanging wall. Rollins et al. discuss mechanisms of 3D postseismic deformation in the southern California plate-boundary region around the Salton Trough following the 2010 M7.2 El Mayor-Cucapah earthquake, using continuous GPS data over a period of 3 years following the event. A wide range of models that can explain the transient displacements is explored, including localized afterslip, Newtonian viscosity, and stress-dependent viscosity in the lower crust and upper mantle.

Hauksson examines correlations between earthquake stress drops in southern California and various conditions. High and low stress drops are generally found near fault jogs and trans-tensional regions, respectively. An increasing rate of shear strain correlates with decreasing stress drops, and heat flow is also shown to correlate significantly with stress drops. The crustal stress regime and style of faulting have lesser effects on stress drops, and essentially no dependency on moment magnitude and event depth is found. The results can be explained in terms of the dependence of fault healing on different variables. In the final paper of the volume, Murotani et al. investigate source rupture area scaling for $\mathrm{Mw}>7.4$ earthquakes on inland mega-fault systems. Information on source rupture processes derived from waveform inversions and geomorphological surveys is used to correlate source area $\mathrm{S}$ with seismic moment Mo. The results indicate three scaling regimes, with $\mathrm{S}$ proportional to $\mathrm{Mo}^{2 / 3}$ for $\mathrm{Mo}<7.510^{18} \mathrm{Nm}, \mathrm{S}$ proportional to Mo for Mo $>1.810^{20} \mathrm{Nm}$, and $\mathrm{S}$ scaling varies from $\mathrm{Mo}^{1 / 2}$ to $\mathrm{Mo}^{2 / 3}$ for intermediate Mo values depending on the thickness of the seismogenic zone.

\section{Acknowledgments}

We are grateful to Silvia Nardi for invaluable help with the organization of the 40th Workshop of the International School of Geophysics on Properties and Processes of Crustal Fault Zones. The workshop was funded by the Istituto Nazionale di Geofisica e Vulcanologia, the European Geosciences Union, and the National Science Foundation (Grant EAR1303569). We thank the authors of the papers for their contributions and the referees for critical reviews that improved the scientific quality of the volume. The latter include Rachel Abercrombie, Mustafa Aktar, Hideo Aochi, Annemarie Baltay, Salvatore Barba, Glenn Biasi, Alvar Braathen, Riccardo Caputo, Ahmed Elbanna, Giulio Di Toro, Benchun Duan, Eric Dunham, Ake Fagereng, Yuri Fialko, Andy Freed, Florian Fusseis, Kathleen Haller, Bor-Shouh Huang, Kerry Kay, Alice Gabriel, Patricia Martinez Garzon, Francesco Mazzarini, Tom Mitchell, Max Moorkamp, Luis Morales, Chris Rollins, Martha Savage, Kate Scharer, Silvio Seno, Bruce Shaw, Zheqiang Shi, Hiroki Sone, Toshiro Tanimoto, Nicola Tisato, Virginia Toy, and Lupei Zhu. 